\title{
Vaccine procurement during an influenza pandemic and the role of Advance Purchase Agreements: lessons from 2009-H1N1
}

Vaccines are hugely important tools in minimising the effect pandemic influenza could have on a population. The reforms introduced by the Pandemic Influenza Preparedness Framework are ill-suited to providing sufficient levels of access to vaccines to meet the needs of developing states, and as such developing states will continue to be reliant upon the traditional methods of vaccine procurement to procure the majority of the vaccines they required. Using procurement during $2009-\mathrm{H} 1 \mathrm{~N} 1$ as a case study, this paper examines the methods of procurement utilised by states in order to determine if the procurement tools available to developing states are sufficient to procure adequate levels of pandemic influenza vaccines. Particular focus is given to the role Advance Purchase Agreements play in the procurement process. By exploring this case study it is possible to argue that these procurement methods are ineffective for developing states, and when the next influenza pandemic occurs, demand will once again outstrip supply globally, due to supply of vaccines being dominated by the developed states with Advance Purchase Agreements in place.

Keywords: procurement; pandemic influenza; global health; access to medicines 


\section{Introduction}

Challenges in vaccine procurement arise when a vaccine is in short supply, and in high demand by many states at the same time, as is the case with pandemic influenza vaccines. Numerous factors make such a scenario particularly concerning, including: firstly, pandemic influenza can spread locally, nationally and globally in a matter of weeks (Colizza, Barrat, Barthelemy, Valleron, Vespignani, 2007; Bonabeau, Toubiana \& Flahault 1998). The first case of 2009-H1N1 was confirmed on April 24th 2009 in Mexico (WHO, 2009a), only one month later forty-six states had reported a total of 12,515 cases (WHO, 2009b); secondly, there is a delay between the pandemic being declared, and doses of a vaccine being administered. During 2009-H1N1 the first vaccination was administered three months after the pandemic was announced (Parry, 2009). These factors coupled with the high levels of mortality and morbidity (World Health Organization, 2010) that may be associated with influenza pandemics (Kilbourne, 2006) means that those pandemic influenza vaccines which can be manufactured may be in demand by many states as soon as they are available, each seeking to access to enough vaccine to meet the needs of the population.

The access and distribution system for pandemic influenza vaccines has garnered significant criticism within the literature (Coker \& Mounier-Jack, 2006, Lee \& Fidler, 2007), and developing states. Most notably in 2005, the Indonesian Government refused to share samples of $\mathrm{H} 5 \mathrm{~N} 1$ with the $\mathrm{WHO}$, and cited an unfair correlation between sharing samples with the WHO and the benefits obtained in return (Sedyaningsih, Isfandari, Soendoro, Supari , 2008). The Indonesian Health Minister at that time claimed that the WHO passed the samples they had provided onto pharmaceutical companies to develop unaffordable commercial vaccines (Butler, 2007). This incident acted as a major impetus for the creation of the WHO PIP Framework, which is considered below.

This paper is a case study on the procurement of pandemic influenza vaccines during 2009-H1N1, and the likely manner in which procurement will occur during future pandemics. This case study serves to highlight how inefficient the procurement methods for pandemic influenza vaccines are for developing states, and the role Advance 
Purchase Agreements play in allowing developed states to dominate the supply of vaccine during a pandemic.

\section{The Traditional Methods of Vaccine Procurement}

Vaccines are obtained by states for their public health vaccination programmes using four principle procurement methods, which are outlined below.

\section{Self-Procurement Directly by State}

Self-procurement, the process of vaccines being purchased from manufacturers directly by governments, represents the majority of vaccines that are procured worldwide $(79 \%)$ (WHO-UNICEF, 2012). Self-procurement has a number of distinct benefits for governments. It allows for the independent selection of manufacturer, which may result in the negotiation of lower unit price, and increased responsiveness to health needs within a state. Such benefits may not be replicable to states who procure via donations, as they rely on the vaccine selection and procurement methods of the donor organisation.

If a government wishes, and has the ability, to self-procure vaccines, additional technical elements of the procurement process must be managed by the state. These include pre-qualification or product licencing, the efficiency of which is considered to be a high priority for the WHO (WHO, 2007); preparation of bidding documents and realisation of the tender; selection of supplier; financial arrangements; and contract and quality monitoring (WHO, 2003). Managing the procurement process requires specialised technical knowledge in the fields of medicine and law, the financial resources to purchase the vaccines, and an appropriate certification process for licensing vaccine safety and efficacy. In the case of influenza vaccines, an appropriate cold-chain infrastructure is also required to store the vaccines. Such advanced infrastructure, knowledge and technical ability (Hinman, 2013) is beyond the capacity of many developing states (Hyde, 2012). For example, the African Region of the WHO is considered to have the weakest infrastructure (WHO, 2012a) in terms of legislative framework and financing, preparedness, and public health emergency response (WHO, 2012b). However, in some instances, if a developing state is using an international 
organisation as a procurement agent, some degree of technical assistance from international organisations may be available for such matters (GAVI, 2011). Advance Purchase Agreements and Vaccine Procurement

Of particular relevance to some self-procuring states are Advance Purchase Agreements (APAs). APAs for vaccine procurement take the form of 'sleeping contracts'; a contract between two parties (in this case, a vaccine manufacturer and a government) which lays dormant and unenforceable until triggered by a pre-determined event, at which stage it becomes legally binding (Kremer \& Glennerster, 2004). The impact APAs have on procurement of pandemic influenza vaccines is considered below.

\section{Donations via international organisations}

As the previous method of self-procuring vaccines on the open market from manufacturers is beyond the healthcare budgets of some developing states ( $\mathrm{Lu}$ et al, 2010; Mahoney, Ramachandran, and Xu 2000; Levine et al, 2011; Hargreaves et al, 2011), a number of non-governmental and inter-governmental organisations, such as the GAVI Alliance (GAVI, 2011b), World Health Organisation (WHO, 2011b), and UNICEF (UNICEF, 2012) provide vaccines to governments. These international organisations acquire vaccines through a number of routes: donations from manufacturers (Towse et al, 2012) and states (WHO, 2011b), or by acting as a procurement agent, purchasing the vaccines directly from the manufacturers either using their own finances, or using finances provided by the states they are procuring on behalf of (World Bank, 2003; DeRoeck et al, 2006). Vaccines are then provided to developing states that lack the capacity to self-procure.

\section{Procured and administered by international organisations}

In some instances, international organisations procure the vaccines and administer them to populations directly (WHO, UNICEF \& the World Bank, 2009). This predominantly occurs when a state lacks the necessary infrastructure to administer the vaccines. In these cases the procurement methods of an international organisation are utilised in the same manner as outlined above, but rather than providing vaccines to a government for 
administration, representatives of the international organisation coordinate, manage and administer the vaccines to the population (Ciglenecki et al, 2013).

\section{Procured via other sources}

Inter-state donations are made directly from one state to another, without using an international organisation as a procurement agent. Inter-state sale of vaccines is where one state sells some vaccine to another. Inter-state sales of vaccines are quite rare, although they did occur during the 2009-H1N1 influenza pandemic, as the case study below discusses.

\section{Vaccine Procurement during an Influenza Pandemic: Case study on 2009-H1N1}

All pandemic influenza vaccines are procured by the national government, and then administered to the population, either in line with the national policy on pandemic influenza management, if the state has one, or on an ad-hoc basis. Therefore, the role of the national government in introducing vaccines into a health system is particularly significant during an influenza pandemic. When faced with an influenza pandemic, immunising 'at risk' populations as soon as possible should become a major public health priority (Mounier-Jack \& Coker, 2006; Uscher-Pines et al, 2006; WHO, 2005). The number of doses which would be required in order for all states to immunise just the 'at risk' populations is much higher than the amount which can be manufactured in the first year of pandemic influenza vaccine manufacturing; WHO currently define at risk groups for influenza vaccines as being 'pregnant women, health-care workers, the elderly, those with risk conditions and children aged 6-59 months' (WHO, 2012d) but the demographic can change with different pandemic strains. Just within the USA it is estimated that approximately 159 million people fall into one or more of the WHO's risk groups for the purposes of influenza vaccination (Swendiman \& Jones, 2009), in the European Union that figure rises to 248.3 million (Ryan et al, 2006), and the maximum number of vaccines that can be manufactured and distributed within the first year of the pandemic is just over one billion doses (Partridge \& Kieny, 2013). Therefore, even on a one-dose vaccination schedule there are insufficient vaccine available to cover the global 'at risk' population, on a two-dose schedule, there are 
scarcely enough vaccine manufactured to immunise the at risk population in the EU \& the USA.

\section{Self-Procurement During 2009-H1N1}

During an influenza pandemic, states are significantly more likely to obtain vaccines, and obtain them earlier in the pandemic if they self-procure, as opposed to being reliant on donations. Four-times as many vaccines were self-procured during 2009-H1N1 than were donated during the same pandemic (WHO, 2013), and donated vaccine arrived in states at least four months after self-procuring states (Partridge \& Kieny, 2010). The fundamental problem facing many developing states reliant upon international organisations for vaccine donations is that a majority of this finite amount of pandemic influenza vaccines which can be manufactured in the first year is already reserved and guaranteed through Advance Purchase Agreements held by many developed states (Verweij, 2009; Hanquet, 2010; Fidler, 2010), or large quantities of the supply is bought by developed states early on in the pandemic. As a result, developing states and international organisations are reliant upon donations from vaccine manufacturers and states with excess vaccines to sell or donate in order to immunise their populations.

\section{The Role of Advanced Purchase Agreements during 2009-H1N1}

APAs for pandemic influenza vaccines are made enforceable by a Phase Six pandemic declaration being made by the WHO. A Phase Six declaration is defined as being when: sustained human-to-human spread of the virus into at least two countries in one WHO region, with community level outbreaks in at least one other country in a different WHO region. Designation of this phase will indicate that a global pandemic is under way. (WHO, 2010d)

The terms of APAs are broad enough to allow governments to reserve doses of vaccine to treat a disease sub-type that may not yet have come into existence. The APA which 
the government of the United Kingdom had in place before the 2009-H1N1 pandemic allowed the government to purchase 132 million doses from two manufacturers (Parliamentary Office for Science and Technology, 2009). However, the minimum number of vaccines procured via an APA appears to have some degree of flexibility. When it became apparent that the 2009-H1N1 pandemic was not as severe as anticipated, a number of states with APAs in place attempted to reduce their allocation; of the eleven states in Europe that attempted to reduce their allocation, all but two were allowed to do so by the manufacturers (European Centre for Disease Prevention and Control, 2011). In terms of pandemic preparedness and response, such a degree of flexibility was clearly highly beneficial to states with APAs in place during 2009-H1N1 in that it allowed a number of states to guarantee the delivery of the maximum number of doses during a particularly severe pandemic, and to reduce their number of guaranteed doses during a less severe pandemic.

Advance Purchase Agreements for pandemic influenza vaccines appear to be common amongst developed states. During 2009-H1N1, of the 53 developed states within the World Trade Organisation, 20 states had an APA in place. Within the European Union alone, sixteen countries had an APA in place prior to the start of the outbreak, and APAs were utilised by Canada, Switzerland, America, and New Zealand during 2009-H1N1. (European Centre for Disease Prevention and Control, 2011; Public Health Agency of Canada, 2012; WHO, 2008, Department of Health and Human Services, 2010; Ministry of Health (NZ), 2009)

The WHO has encouraged use of APAs by developing states, in order to 'increase equity in supply and support advance planning for administration of vaccines.' (World Health Organisation, 2012b), and commitments have been made from pharmaceutical companies such as GlaxoSmithKline that they 'would supply [vaccines via an APA] at tiered prices, based on the gross national income of the nation' (GSK, 2011; GSK 2008). Despite this, it may still be unrealistic to expect states with limited healthcare budgets (a fact noted by GlaxoSmithKline (GSK, 2008)) to spend a large proportion of that budget on maintaining a contract that guarantees vaccines for a pandemic which may not occur in the next five, ten, or even twenty years. This is particularly noticeable 
given that the per capita government expenditure on healthcare has an average of \$12USD in least-developed states, \$56.8USD in low-middle income (developing) states, \$275USD in upper-middle income (developing) states and \$2,186USD in developed states (WHO, 2012c).

APA are maintained by states paying an annual 'Pandemic Preparedness Fee' to the manufacturer. Whilst the exact costs of maintaining an APA by way of a Pandemic Preparedness Fee are not publicly available, a system whereby states are required to pay to maintain contracts for vaccines that may not even be required over the course of the contract's life may be financially prohibitive, or not fit the spending priorities for many developing states. On the point of costs, it was confirmed during a UK House of Lords Science and Technology Committee report into the UK pandemic preparedness plans that whilst the vaccines for pandemic influenza which are reserved via an APA are paid for at the point of purchase during a pandemic, during the dormant phase the Agreements are maintained by the government paying 'Pandemic Preparedness Fees' to maintain the contract (House of Lords Science and Technology Committee, 2005). At the time the report was drafted the Minster responsible claimed it was 'rather difficult to give exact figures' as to the cost of the Pandemic Preparedness Fee associated with maintaining the UK's APA, as negotiations were still ongoing (House of Lords Science and Technology Committee, 2005). A Freedom of Information request made to the Department of Health to determine the cost of the Pandemic Preparedness Fee was refused on the basis that making such information available could "potentially limit the contractor's negotiating position with other customers if this information was put in the public domain" (communication held on file by the author, 2014). Full access to the terms of developed state's APA's would provide an avenue of potential future research in this field, in order to determine the exact impact such agreements have on access.

During 2009-H1N1, many Advance Purchase Agreements held by developed states were triggered, providing them with guaranteed priority access to vaccines. These states also bought vaccines to cover a large proportion of their population in the early stage of 
the 2009-H1N1 influenza pandemic. Vaccine manufacturers were unable to take or fulfil orders from many developing states, or international organisations on behalf of developing states, in the early stages of production. It is estimated that it will take approximately one year for vaccine manufacturers to complete all APA orders, if no states reduce their APA allocation (Parliamentary Office for Science and Technology, 2009).

The impact APAs have on access to vaccine during a pandemic appears to be significant. A 2009 survey by the World Health Organisation of pandemic influenza vaccine manufacturers asked whether they would be willing to reserve $10 \%$ of real-time production for acquisition by United Nations agencies, 14 out of 25 were unable to meet the request to set aside $10 \%$ of their production capacity, because they were constrained by meeting the volume of vaccines reserved via APAs (Collin \& de Radiguès, 2009). Despite the changes made to vaccine procurement by the PIP Framework, it appears as if the commitment to supply $10 \%$ of real-time vaccine manufacturing capacity to the WHO under the PIP Framework has not altered the impact APAs will have on access to vaccines during the next pandemic. APA contracts that are in place during the next pandemic will be serviced alongside the $10 \%$ of vaccine production committed to WHO, however, the vaccine reserved via APAs will be distributed prior to orders from states without APAs in place. Given the fact that APAs are only held by developed states, it appears that middle-income and developing states will predominantly be inhibited from accessing vaccine due to these agreements.

\section{Donated Vaccine During 2009-H1N1}

Australia, Canada, the USA, the UK, Japan, France and the Netherlands were some of the first states to receive vaccine during 2009-H1N1 (Verweij 2009), and in an attempt to increase access to vaccines for developing states the WHO requested these states to donate a proportion of the vaccine to them to distribute to developing nations at risk of the outbreak (WHO, 2011b). However, it was noted that "WHO and developing countries had little leverage to influence developed countries other than rhetoric about equity, justice, and solidarity" (Fidler, 2010 p.2). Despite the fact that nearly 120 million 
doses were pledged to the WHO by the USA, Australia, Brazil, France, Italy, New Zealand, Norway, Switzerland, and the UK (WHO, 2011b), these states only began shipping doses after it became apparent that a one-dose regime would suffice to immunise adults. This halved the amount of vaccine these states would require to meet immunisation goals (WHO, 2011b), and coincided with the confirmation that the threat posed by the 2009-H1N1 was not as severe as first thought (Neuzil, 2009; Greenberg et al, 2009; Clark et al, 2009; BBC News, 2009). The outcome of the two major studies considering the efficacy of a one-dose strategy (Greenberg et al, and Clark et al) were made available on 17th December 2009, and the first shipments of donated vaccine arrived in recipient states in late January 2010 (WHO, 2011b) despite the fact that it had been available in developed states, in comparatively much larger quantities, since October 2009 (Schwarzinger et al , 2010; CDC, 2010).

In addition to the doses pledged to the WHO, some developed states with excess vaccine commenced inter-state sales of vaccine during 2009-H1N1. In November 2009 the Netherlands announced the sale of fifty-five per cent of the vaccines for 2009-H1N1 that they had procured via their APA; the following month Germany placed just over four per cent of their APA allocation on the open market, and in January 2010 France announced that 'part' of their allocation would be sold to other states. (BBC News, 2010)

As 2009-H1N1 was not as severe as initially anticipated, vaccine uptake was low in these states, and only a one-dose vaccination strategy was required to provide immunity, whereas a two-dose strategy is more common (Fauci, 2006); as a result, there were excess vaccine doses in several states who had procured vaccine early on in the pandemic. Such factors clearly made governments' decision to sell, or donate purchased vaccines easier (Fidler, 2010).

It appears as if the move to a one dose strategy, meaning that some developed states held excess doses of the vaccine, may have factored in the decision making process of some donor states. For example, US Health and Human Services Secretary, Kathleen Sebelius, told the Associated Press that "as the US is flush enough [with vaccines, now that a one-dose strategy will suffice] the long-promised donation of 25 million doses to developing countries is ready to ship."(Neergaard, 2010). Furthermore, the 
commitments to donate vaccines which were made by manufacturers during 2009H1N1 were made without specifying a delivery date or timeframe, despite the fact that these manufacturers were already producing and shipping vaccine to self-procuring states when the pledge to donate was made.

Developing states being reliant upon manufacturers and developed states to donate vaccines for their population during an influenza pandemic resulted in a scenario whereby during the 2009-H1N1 outbreak when the WHO distributed 78 million doses of pandemic influenza vaccine (donated by vaccine manufacturers and states with excess supply), over 30 million of these doses were delivered to developing states at least three months later than developed states in the 'post-pandemic phase' (WHO, 2011b), when the virus' transmission levels and intensity is considered more akin to a seasonal influenza outbreak, than that of a pandemic (WHO, 2014).

During these three months a further 7000 deaths were recorded from 2009-H1N1 by the World Health Organization, predominantly in developing states (WHO, 2009b). Whilst this is a relatively low figure, when compared with the population of developing states, it is worth bearing in mind that 2009-H1N1 was a particularly mild pandemic (WHO, 2013;) when compared with previous influenza pandemics (Kilbourne, 2006), and during a more severe pandemic the number of deaths during this period would have certainly have been higher. Moreover, the fact that international organisations were solely reliant upon the goodwill of states with excess vaccines or manufacturers for donations of vaccines, is particularly concerning. During a more severe pandemic in the future, those states that have purchased or reserved vaccines for their own population may very well be reluctant to donate or sell them. 
Fig1. Distribution and sources for pandemic A(H1N1) 2009 vaccine doses, by region $†$

\begin{tabular}{|c|c|c|c|c|}
\hline Regien & $\begin{array}{c}\text { Total no. of doses } \\
\text { recelved from all } \\
\text { sources } t\end{array}$ & $\begin{array}{c}\text { \%ol vacine } \\
\text { recelved as } \\
\text { deplayment from } \\
\text { WHO }\end{array}$ & $\begin{array}{l}\text { \% of vaccine } \\
\text { procured through } \\
\text { government } \\
\text { purchases }\end{array}$ & $\begin{array}{l}\text { \% cf vacclne } \\
\text { procured from other } \\
\text { sources }\end{array}$ \\
\hline$A F F$ & $77,955,078$ & 945 & G. $5 \%$ & ก.0\% \\
\hline$A M R$ & $143,968,890$ & $7.0 \%$ & $79.0 \%$ & $14.0 \% 6$ \\
\hline [MMR & $20,734,600$ & $403 \%$ & $42.9 \%$ & $16.8 \% 6$ \\
\hline EUR & $230,715,990$ & $0.8 \%$ & $98.8 \%$ & $0.4 \%$ \\
\hline SEAR & $23,110,200$ & $91.2 \%$ & 8.75 & $0.2 \%$ \\
\hline W'PR & $193, \mathrm{C} 89,000$ & $1.5 \%$ & $15.1 \%$ & $30.4 \%$ \\
\hline Total & $6: 2,702,320$ & $12.3 \%$ & $59.4 \%$ & $28.3 \%$ \\
\hline
\end{tabular}

Table reproduced from: (World Health Organization, 2013)

AFR - African Region; AMR - Region of the Americas; EMR - Eastern Mediterranean

Region; EUR - European Region; SEAR - South- East Asian Region; WRP - Western

Pacific Region

As can be seen from figure 1, during the 2009-H1N1 pandemic over 634 million doses of vaccine were procured by states. The majority of vaccines obtained by states were via central government purchases (59.4\%), with $28.3 \%$ vaccines being procured from other sources, and $12.3 \%$ of vaccines deployed internationally being donated via the WHO's Vaccine Deployment Initiative (VDI). The VDI was a department within the WHO charged with managing and coordinating the global donation of 2009-H1N1 vaccines, and the resources needed to deploy them, and was created specifically to manage the distribution of vaccines for $2009-\mathrm{H} 1 \mathrm{~N} 1$. Although only $12.3 \%$ of vaccines were donated by the WHO, donations accounted for $94.5 \%$ of the African Region's vaccines, $91.2 \%$ of vaccines utilised in the South-East Asia Region. Although all regions acquired some vaccines via self-procurement, this ranged from $98.8 \%$ in Europe, to only $6.5 \%$ in Africa.

Self-procurement dominated the supply of vaccines during 2009-H1N1, and a state was much more likely to obtain vaccines if they self-procured, rather than if they were reliant upon donations. This can be demonstrated by considering the European and African Regions' experience during 2009-H1N1 who at the time of the outbreak had 
fairly similar populations of around 800 million people (WHO, 2010c; OECD, 2010), but the procurement methods utilised by the states within these regions differed significantly. European states acquired $98.8 \%$ of their vaccines via self-procurement, and procured enough to immunise $27.5 \%$ of their population on a one dose strategy (WHO, 2013). Whereas in Africa $94.5 \%$ of the vaccines utilised were donated by the WHO, but only $3.9 \%$ of the population was immunised (WHO, 2013).

\section{Post 2009-H1N1 Developments}

\section{The Pandemic Influenza Preparedness Framework}

The methods by which states pandemic influenza vaccine donations were gathered and managed were subject to reform in 2011, with the introduction of the Pandemic Influenza Preparedness Framework (PIP Framework) via the WHO. The WHO has long played an integral role in the response to influenza pandemics Gostin, 2014: P.367-378), although the effectiveness of the The PIP Framework sets out to increase access to pandemic influenza vaccines by enabling the WHO to manage a stockpile of around 150 million vaccines; "50 million doses of the stockpile will be for use in 'affected countries, according to public health risk and need, to assist in containing the first outbreak or outbreaks of an emerging pandemic and 100 million for distribution....to developing countries that have no or inadequate access to....influenza vaccines, on a per capita basis that can be distributed to affected and at risk developing states during a pandemic" (WHO, 2011a).

This stockpile is created by requiring vaccine manufacturers who receive pandemic influenza virus samples from the WHO for vaccine development, to conclude a Standard Material Transfer Agreement (SMTA2). In these Agreements, in return for receiving virus samples, manufacturers commit to at least two of the following:

"Donate at least $10 \%$ of real time pandemic vaccine production to WHO.

Reserve at least $10 \%$ of real time pandemic vaccine production at affordable prices to WHO. 
Donate at least $\mathrm{X}$ treatment courses of needed antiviral medicine for the pandemic to WHO.

Reserve at least $\mathrm{X}$ treatment courses of needed antiviral medicine for the pandemic at affordable prices". (WHO, 2011a)

So far, only two out of twenty-five influenza vaccine manufacturers, have concluded SMTA2 Agreements (WHO, 2012e), and despite the PIP Framework claiming manufacturers must donate or reserve at least $10 \%$ of real time vaccine production, GSK have committed to donating 7.5\% and reserving 2.5\% of their production (Along with donating 2 million doses of antivirals and reserving 8 million doses of antivirals at affordable prices) (WHO, 2012f), and Sanofi Pasteur have committed to donating 7.5\% and reserving $7.5 \%$ of their real-time pandemic influenza vaccine production (WHO, 2012g). The fact that so few SMTA2 Agreements have been concluded, and those that have, appear to have weaker than anticipated commitments on the part of vaccine manufacturer's points towards the lack of impact the Framework will have on access to vaccine. There is an ongoing need to monitor the content of the SMTA2 Agreements that are concluded, and determine to what extend they differentiate from the terms laid down by the WHO in the Framework.

A number of commentators have expressed concerns that the benefit sharing requirements of the Framework will not result in significant improvements in access to vaccine during a pandemic for developing states for two principal reasons. Firstly, the Framework has only imposed minimal changes on the existing market-based economy surrounding influenza vaccine production and procurement (Kamradt-Scott \& Lee, 2011). Secondly, initiatives to encourage donations of vaccine to the $\mathrm{WHO}$, similar to those detailed in the Framework, have already been implemented outside of the Framework without significantly improving access to vaccine for developing states (Vezzani, 2010). 
The idea that the PIP Framework has done little to change the market-based economy for vaccines, and will therefore have very little impact upon developing states ability to offer national vaccination programmes, and the benefit-sharing system in the Framework appears to be wholly insufficient to rectify inequities in access to vaccines during a pandemic. As Rhodes states: 'In terms of a simple calculation, the 100 million doses from the stockpile that will be allocated to developing countries on a per capita basis, would, even if a single dose regime was viable, cover approximately $1.8 \%$ of their populations.' (Rhodes, 2012)

Whilst the true impact of the Framework will not be seen until it is utilised during an influenza pandemic, it is likely the impact it could have will be somewhat negligible, and the need for states to procure at least some, if not the majority, of their vaccines via the traditional procurement methods will continue. In light of this, the methods by which states procure vaccines outside of the PIP Framework, and the impact these procurement methods have on the likelihood of a state obtain vaccine during an influenza pandemic is crucial.

\section{Pandemic Influenza Manufacturing Capacity}

As this paper only considers vaccine procurement during 2009-H1N1 it would not be appropriate to draw absolute conclusions from it, and generalisations based on 2009H1N1 may have limited predicative power for a number of reasons. Firstly, the global manufacturing capacity has expanded since 2009; the most recent survey of vaccine manufactures shows capacity grew from 876 million doses per annum in 2009 (Partridge \& Kieny, 2010), to 1420 million doses per annum in 2011 (Partridge \& Kieny, 2013). Secondly, 2009-H1N1 was not as severe as anticipated thereby increasing the number of vaccines which were available for developing states; there is no guarantee that developed states will behave in this manner should the next pandemic be more severe. 
Some generalisations from vaccine procurement during 2009-H1N1 may, however, be justified. As outlined at the introduction, the impact the Pandemic Influenza Preparedness Framework will have on access to vaccines during a pandemic looks to be limited. Furthermore, whilst manufacturing capacity has grown since $2009,75 \%$ of this capacity is dedicated to meeting the needs of the 'Northern Hemisphere' (Partridge \& Kieny, 2013). While there have been changes to the manner in which the WHO procures vaccines for donation to developing states since 2009 via the PIP Framework, these will arguably have a limited impact overall, and vaccine procurement during the next pandemic will occur in a similar manner to 2009-H1N1. Finally, whilst influenza vaccine manufacturing capacity may have grown by 620 million doses between 2009 and 2011, human population grew by 170 million in the same period from 6.81 billion (Population Reference Bureau, 2009) to 6.98 billion (Population Reference Bureau, 2012), with population growth predominantly occurring in least-developed states (Population Reference Bureau, 2012). Whilst capacity grew faster than population during this period, it did not grow to such an extent that it will have a significant impact on access to vaccine if the next influenza pandemic occurs in the near future, and manufacturing capacity and population growth continue to follow the same trends.

\section{Conclusion}

The above factors mean that, despite the improvement the PIP stockpile may have on access to vaccines for developing states, when the next influenza pandemic occurs demand will once again outstrip supply amongst developing nations, in much the same way as occurred during 2009-H1N1. Aside from the small number of doses which developing state may be provided from the PIP stockpile, the traditional methods states use to procure vaccines during a pandemic will continue to result in a scenario whereby developing states are least likely to gain timely access to pandemic influenza vaccines on behalf of their populations; this means that during when the next influenza pandemic occurs it is unlikely that developing states are going to be in a significantly better position to procure the vaccines they need than they were during 2009-H1N1. 
Word Count: 6557

BBC News, 'Poorer Nations Get Swine Flu Jabs' (London: 12 October 2009) http:// news.bbc.co.uk/2/hi/health/8302416.stm.

BBC News, 'France Sells off Surplus Swine Flu Vaccine' (London: Sunday 3 January 2010) http://news.bbc.co.uk/1/Hi/Health/8438663.Stm

Bonabeau E., Toubiana L., \& Flahault A. (1998) 'The Geographical Spread of Influenza'Proceedings of the Royal Society of London. Series B: Biological Sciences 265 (1413) 2421-2425.

Butler, (2007) 'Q\&A: Siti Fadilah Supari', Nature, 450 (1137)

Centers for Disease Control and Prevention, (2010) 'Interim results: Influenza A(H1N1) 2009 Monovalent Vaccination Coverage - United States, October-December 2009' Morb Mortal Wkly Rep 59

Ciglenecki, I., Sakoba, K., Luquero, F. J., Heile, M., Itama, C., Mengel, M.,... \& Legros, D. (2013). Feasibility of mass vaccination campaign with oral cholera vaccines in response to an outbreak in Guinea. PLoS medicine, 10(9), e1001512.

Coker, R. and Mounier-Jack, S. (2006). Pandemic Influenza Preparedness in the AsiaPacific Region. Lancet, 368: 886-889.

Collin, N., \& de Radiguès, X. (2009). Vaccine production capacity for seasonal and pandemic (H1N1) 2009 influenza. Vaccine, 27(38), 5184-5186. 
Colizza, V., Barrat, A., Barthelemy, M., Valleron, A. J., \& Vespignani, A. (2007).

Modelling the worldwide spread of pandemic influenza: baseline case and containment interventions. PLoS Medicine, 4(1), e13.

Department of Health, (2009) 'Agreements Secured for Pre-Pandemic Vaccine for the UK, (London: 15 May 2009)

http://webarchive.nationalarchives.gov.uk/+/www.dh.gov.uk/en/Publichealth/Flu/ $\underline{\text { Swineflu/DH_099248 }}$

Department of Health and Human Services (2010), 'Pandemic Influenza Plan Supplement 6 Vaccine Distribution and Use' http://www.hhs.gov/pandemicflu/plan/ sup6.html

DeRoeck, D., Bawazir, S. A., Carrasco, P., Kaddar, M., Brooks, A., Fitzsimmons, J., \& Andrus, J. (2006). Regional group purchasing of vaccines: review of the Pan American Health Organization EPI revolving fund and the Gulf Cooperation Council group purchasing program. The International journal of health planning and management, 21(1), 23-43.

European Centre for Disease Prevention and Control (2011), 'VENICE II Pandemic A(H1N1) 2009 Influenza Vaccination Survey, Influenza season 2009/2010’ http:// venice.cineca.org/Final_Report_VENICE_Pandemic_I nfluenza_2009.pdf

Fauci (2006), 'Seasonal and Pandemic Influenza Preparedness: Science and Countermeasures', Journal of Infectious Diseases, 194 
Fidler (2010), 'Negotiating Equitable Access to Influenza Vaccines: Global Health Diplomacy and the Controversies Surrounding Avian Influenza H5N1 and Pandemic Influenza H1N1' PLoS Med 7(5)

GlaxoSmithKline (Memorandum) (2008), House of Lords Select Committee On Intergovernmental Organisations (Written Evidence), Diseases Know No Frontiers: How Effective Are Intergovernmental Organisations In Controlling Their Spread? Session 2007-2008, HL 143-I http://www.publications.parliament.uk/pa/ld200708/ ldselect/ldintergov/143/143.pdf

GlaxoSmithKline (2011), ‘Pandemic Preparedness Policy’ http://www.gsk.com/content/ dam/gsk/globals/documents/pdf/Policies/pandemic-preparedness.pdf;

Global Alliance on Vaccine Innovation (2011), 'The GAVI Alliance Vaccine Supply and Procurement Strategy for the Period 2011-2015' www.gavialliance.org/library/gavi.../ gavi-alliance-procurement-policy/

Global Alliance on Vaccine Innovation (2011), GAVI Alliance Revised Co-financing Policy, http://www.gavialliance.org/library/gavi-documents/policies/gavi-alliance$\underline{\text { revised-co-financing-policy/ }}$

Gostin (2014) 'Global Health Law': Harvard University Press

Hanquet G. (2010), 'Lessons Learnt from Pandemic A(H1N1) 2009 Influenza Vaccination; Highlights of a European Workshop in Brussels', Vaccine, (29)3 370-377;

Hargreaves J., Greenwood B., Clift C., Goel A., Roemer-Mahler A., Smith R., Heymann D. (2011) 'Making New Vaccines Affordable: A Comparison of Financing Processes 
Used to Develop and Deploy New Meningococcal and Pneumococcal Conjugate Vaccines' The Lancet 378(9806) 1885-1893.

Hinman, A. (2013). Perspectives on sustainable vaccine introduction. Vaccine, 31, C8C9.

House of Lords Science and Technology Committee (2005), 'Pandemic Influenza: Report with Evidence', 4th Report of Session 2005-06, HL Paper 88 http:// www.publications.parliament.uk/pa/ld200506/ldselect/ldsctech/88/8802.htm

Hyde T., Dentz H., Wang S., Burchett H., Mounier-Jack S., Mantel C., (2012) 'The New Vaccine Introduction Impact Published Literature Working Group, The Impact Of New Vaccine Introduction On Immunization And Health Systems: A Review Of The Published Literature', Vaccine, 30(45) 6347-6358

Jorgensen P., Wasley A., Mereckiene J., Cotter S., Weber J., Brown C., (2013) 'Unequal Access to Vaccines in the WHO European Region during the A (H1N1) Influenza Pandemic in 2009.' Vaccine 31(38)

Kamradt-Scott, A., \& Lee, K. (2011). The 2011 Pandemic Influenza Preparedness Framework: Global Health Secured or a Missed Opportunity? Political Studies, 59(4), 831-847.

Kilbourne, E. D. (2006). Influenza pandemics of the 20th century. Emerging infectious diseases, 12(1), 9 .

Kremer, M., \& Glennerster, R. (2004). Strong medicine: creating incentives for pharmaceutical research on neglected diseases. Princeton University Press. 
Lee, K. \& Fidler, D. (2007) Avian and pandemic influenza: Progress and problems with global health governance, Global Public Health: An International Journal for Research, Policy and Practice 2(3)

Levine, O. S., Bloom, D. E., Cherian, T., de Quadros, C., Sow, S., Wecker, J., ... \& Greenwood, B. (2011). The future of immunisation policy, implementation, and financing. The Lancet, 378(9789), 439-448.

Lu, C., Schneider, M. T., Gubbins, P., Leach-Kemon, K., Jamison, D., \& Murray, C. J. (2010). Public financing of health in developing countries: a cross-national systematic analysis. The Lancet, 375(9723), 1375-1387.

Mahoney, R. T., Ramachandran, S., \& Xu, Z. Y. (2000). The introduction of new vaccines into developing countries II. Vaccine financing. Vaccine, 18(24), 2625-2635.

Matthias, D., Robertson, J., Garrison, M.., Newland, S., \& Nelson, C. (2007). Freezing temperatures in the vaccine cold chain: a systematic literature review. Vaccine, 25(20), 3980-3986

Ministry of Health (NZ) (2009), 'HR20091144 Purchase of Baxter Vaccine Novel Influenza A(H1N1)-09'

http://www.health.govt.nz/system/files/documents/pages/health-report-purchasevaccine $0 . p d f$

Mounier-Jack, S., \& Coker, R. (2006). How prepared is Europe for pandemic influenza? Analysis of national plans. The Lancet, 367(9520), 1405-1411. 
Neergaard, 'Too Much Flu Vaccine? Shot Push This Week to Tell, The Seattle Times

(Washington) Monday, January 11, 2010 http://seattletimes.com/html/health/

2010765241 apusmedhealthbeatfluwhatsnext.html)

Neuzil, K. (2009). Pandemic influenza vaccine policy_considering the early evidence. New England Journal of Medicine, 361(25), 2424-2435.

OECD. (2010), 'Health at a Glance: Europe', OECD Publishing. http://dx.doi.org/ 10.1787/health_glance-2010-en

Parry, J. (2009). China gears up for swine flu vaccination as virus spreads inland. $B M J, 339$.

Parliamentary Office for Science and Technology (2009), 'Post note; H1N1 'Swine Flu' Vaccine', Number 331, www.parliament.uk/briefing-papers/POST-PN-331.pd

Partridge, J., \& Kieny, M. P. (2010). Global production of seasonal and pandemic (H1N1) influenza vaccines in 2009-2010 and comparison with previous estimates and global action plan targets. Vaccine, 28(30), 4709-4712.

Partridge, J., \& Kieny, M. P. (2013). Global production capacity of seasonal influenza vaccine in 2011. Vaccine, 31(5), 728-731.

Population Reference Bureau (2009), '2009 World Population Data Sheet', available at: http://www.prb.org/pdf09/09wpds_eng.pdf

Population Reference Bureau (2012), '2011 World Population Data Sheet', http:// www.prb.org/pdf11/2011population-data-sheet_eng.pdf 
Public Health Agency of Canada (2012), 'The Canadian Pandemic Influenza Plan for the Health Sector' http://www.phac-aspc.gc.ca/cpip-pclcpi/.

Rhodes, C. (2012). Sovereign Wrongs: Ethics in the Governance of Pathogenic Genetic Resources. Ethics in Biology, Engineering and Medicine, 3(1-3).

Ryan, J., Zoellner, Y., Gradl, B., Palache, B., \& Medema, J. (2006). Establishing the health and economic impact of influenza vaccination within the European Union 25 countries. Vaccine, 24(47), 6812-6822.

Schwarzinger, M., Flicoteaux, R., Cortarenoda, S., Obadia, Y., \& Moatti, J. P. (2010). Low acceptability of A/H1N1 pandemic vaccination in French adult population: did public health policy fuel public dissonance? PLoS One, 5(4), e10199.

Sedyaningsih, E., Isfandari ,S., Soendoro ,T., Supari S. (2008). Towards mutual trust, transparency and equity in virus sharing mechanism: the avian influenza case of Indonesia. Annals of the Academy of Medicine, Singapore 37(6) 482-8

Swendiman, K. \& Jones L., (2009) 'The 2009 Influenza A(H1N1) Outbreak: Select Legal Issues' Congressional Research Service

Towse, et al (2012). 'Drugs And Vaccines For Developing Countries' In Danzon \& Nicholson (eds) The Oxford Handbook of the Economics of the Biopharmaceutical Industry, OUP, 302-310; 
UNICEF, 'Supply Annual Report: 2011', (2012) available at: http://www.unicef.org/ supply/files/UNICEF_Supply_Annual_Report_2011_web.pdf (last accessed 24/02/2014);

Uscher-Pines, L., Omer, S. B., Barnett, D. J., Burke, T. A., \& Balicer, R. D. (2006). Priority setting for pandemic influenza: an analysis of national preparedness plans. PLOS medicine, 3(10), e436.

Verweij, M. (2009). Health Inequities in Times of a Pandemic. Public Health Ethics, 2(3), 207-209.

Vezzani, S. (2010). Preliminary Remarks on the Envisaged World Health Organization Pandemic Influenza Preparedness Framework for the Sharing of Viruses and Access to Vaccines and Other Benefits. The Journal of World Intellectual Property, 13(6), 675-696.

The World Bank (2003), Procurement of Health Sector Goods: Pharmaceuticals, Vaccines, and Condoms, World Bank, Washington

World Health Organisation (2003), 'Procurement of Vaccines for Public-Sector Programmes' WHO/V\&B/23.16 http://apps.who.int/medicinedocs/documents/ s17716en/s17716en.pdf

World Health Organisation (2005), 'Checklist for Influenza Pandemic Preparedness Planning'WHO/CDS/CSR/GIP/2005.4 http://www.who.int/influenza/resources/ documents/FluCheck6web.pdf 
World Health Organisation (2008), Pandemic Influenza Preparedness Assessment Report - Switzerland' available at: http://www.bag.admin.ch/influenza/

$\underline{01120 / 01132 / 10097 / 10098 / \text { index.html? }}$

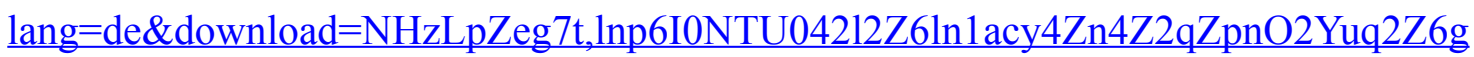
pJCGfIJ6f2ym162epYbg2c JjKbNoKSn6A--

World Health Organisation (2007), 'Guidelines On Regulatory Preparedness For

Human Pandemic Influenza Vaccines' 'WHO/TRS/963 available at: http://www.who.int/ biologicals/vaccines/Annex 2 WHO TRS 963-3.pdf

World Health Organisation, Global Alert and Response Influenza A(H1N1) - Update 1 (24th April 2009a) Available at: http://www.who.int/csr/don/2009 04 24/en/

World Health Organisation, Global Alert and Response Influenza A(H1N1) - Update 38 (25th May 2009b) available at: http://www.who.int/csr/don/2009_05_25/en/

World Health Organisation (2009c), 'Pandemic (H1N1) 2009 Vaccine Deployment Update - 02 August 2009'. Available: http://www.who.int/csr/disease/swineflu/action/ h1n1_vaccine_deployment_update20100802.pdf.

World Health Organisation (2009d), 'Global Alert and Response (GAR), Pandemic (H1N1) 2009 - update 81', in Update of: 30 December 2009, available at: http:// www.who.int/csr/don/2009_12_30/en/index.html, (2009).

World Health Organization (2010a), 'Pandemic (H1N1) 2009 - update 100', in Disease Outbreak News (World Health Organization), 
World Health Organization (2013), 'Global Survey on National Vaccine Deployment and Vaccination Plans for Pandemic A(H1N1) 2009 Vaccine' $\underline{\text { http://www.who.int/ }}$ influenza vaccines plan/resources/2010 H1N1 NVDP WHO Survey.pdf

World Health Organisation (2010c), The African Regional Health Report: The Health of the People http://www.who.int/bulletin/africanhealth/en/;

World Health Organisation (2010d) 'Pandemic Influenza Preparedness and Response: a WHO Guidance Document'WC/515 http://whqlibdoc.who.int/publications/ 2009/9789241547680_eng.pdf

World Health Organisation (2011a), Pandemic influenza preparedness Framework for the sharing of influenza viruses and access to vaccines and other benefits

World Health Organisation (2011b), Main Operational Lessons from the WHO Pandemic Influenza A(H1N1) Vaccine Deployment Initiative, WC/515 http:// www.who.int/influenza_vaccines plan/resources/

hln1_vaccine deployment initiaitve moll.pdf

World Health Organisation (2012a), 'Summary of the 2011 State Parties Report on the IHR Core Capacity Implementation (International Health Regulations 2005) WHO/ HSE/GCR/2010.10 http://www.who.int/ihr/publications/WHO_HSE_GCR_2012.10eng/ $\underline{\mathrm{en} /}$

World Health Organisation (2012b), 'Strengthening Response to Pandemics and Other Public-Health Emergencies: Report of the Review Committee on the Functioning of the International Health Regulations (2005) and on Pandemic Influenza (H1N1) 2009' WA/ 32/1 http://www.who.int/ihr/publications/RC report/en/ 
World Health Organisation (2012c), 'Global Health Expenditure Atlas', W/74 http:// apps.who.int/nha/atlasfinal.pdf

World Health Organisation (2012d), 'Meeting of the Strategic Advisory Group of Experts on Immunization, April 2012 - Conclusions and Recommendations', Weekly Epidemiological Record, 87

World Health Organisation (2012e), Updates on Standard Material Transfer Agreements-2 available at: http://www.who.int/influenza/pip/benefit_sharing/smta2/ en/

World Health Organisation (2012f), Standard Material Transfer Agreement-2 with GSK available at: http://www.who.int/influenza/pip/benefit_sharing/ gsk smta2 dec 2012.pdf?ua $=1$

World Health Organisation (2012g), Standard Material Transfer Agreement-2 with Sanofi Pasteur available at: http://www.who.int/influenza/pip/benefit sharing/ sanofi_smta2 feb_2014.pdf?ua $=1$

World Health Organisation (2014), 'Global Alert and Response: What is PostPandemic?' available at: http://www.who.int/csr/disease/swineflu/ frequently asked questions/post_pandemic/en(last accessed: 26/02/2014) 
World Health Organisation-UNICEF, Trend in the Immunization Financing Indicators reported via the Joint Reporting System 2010, (2012) available at: http://www.who.int/ immunization financing/analyses/jrf analysis/en/index2.html (last accessed: $\underline{25 / 02 / 2014)}$

WHO, UNICEF \& the World Bank (2009), State of the World's Vaccine and Immunization, $3^{\text {rd }}$ ed, available at: http://whqlibdoc.who.int/publications/ 2009/9789241563864_eng.pdf at XXIV 